Article

\title{
Food Composition Impacts the Accuracy of Wearable Devices When Estimating Energy Intake from Energy-Dense Food
}

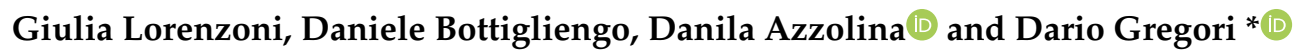 \\ Unit of Biostatistics, Epidemiology and Public Health, Department of Cardiac, Thoracic, Vascular Sciences and \\ Public Health, University of Padova, 35131 Padova, Italy; giulia.lorenzoni@unipd.it (G.L.); \\ daniele.bottigliengo@studenti.unipd.it (D.B.); danila.azzolina@unipd.it (D.A.) \\ * Correspondence: dario.gregori@unipd.it; Tel.: +39-049-8275384
}

Received: 1 April 2019; Accepted: 21 May 2019; Published: 24 May 2019

check for updates

\begin{abstract}
The present study aimed to assess the feasibility and reliability of an a3utomatic food intake measurement device in estimating energy intake from energy-dense foods. Eighteen volunteers aged 20-36 years were recruited from the University of Padova. The device used in the present study was the Bite Counter (Bite Technologies, Pendleton, USA). The rationale of the device is that the wrist movements occurring in the act of bringing food to the mouth present unique patterns that are recognized and recorded by the Bite Counter. Subjects were asked to wear the Bite Counter on the wrist of the dominant hand, to turn the device on before the first bite and to turn it off once he or she finished his or her meal. The accuracy of caloric intake was significantly different among the methods used. In addition, the device's accuracy in estimating energy intake varied according to the type and amount of macronutrients present, and the difference was independent of the number of bites recorded. Further research is needed to overcome the current limitations of wearable devices in estimating caloric intake, which is not independent of the food being eaten.
\end{abstract}

Keywords: energy intake; energy-dense food; automatic food intake measurement

\section{Introduction}

Eating habits are well known to play a key role in affecting the onset and the clinical course of noncommunicable diseases [1]. Promoting population health through a healthy diet might represent one of the primary goals of public health policies worldwide [2].

The adoption of a healthy diet requires a detailed assessment of the population's actual dietary habits [3], allowing for the identification of unhealthy dietary patterns (e.g., excess caloric intake) and their subsequent modification in favor of healthier habits. Dietary assessment is relevant for both primary and secondary prevention of noncommunicable diseases. First, dietary assessment is directed at healthy subjects to maintain their health status (primary prevention of noncommunicable diseases). Dietary assessment is even more relevant to monitor compliance with recommended dietary patterns and prevent complications in subjects already affected by noncommunicable diseases.

However, dietary assessment represents a matter of concern. Several tools are available (food frequency questionnaire, food diaries, 24-h dietary recall) to measure food intake, and they are widely used in clinical research. Unfortunately, such traditional methods present several limitations, such as underreporting (due to recall and desirability biases), poor precision in reporting portions size, and details of food preparation [4]. Therefore, it has been shown that self-reported caloric intake might be inaccurate. In recent years, there has been growing interest in the development of technological tools to objectively assess food intake, overcoming the limitations of traditional dietary assessment methods. 
Several tools have been developed to date, by different modes of action [5]. Some tools consist of the recording of chewing and swallowing movements [6] using an ad hoc microphone (e.g., AutoDietary [7]) or a piezoelectric sensor (Piezoelectric sensor-based necklace with accelerometer [8]). Such tools look similar to a necklace (incorporating the device, allowing for the recording of swallowing). Briefly, data stored are sent to a smartphone for food recognition through ad hoc algorithms. Other tools estimate food intake through the recording of food pictures (e.g., e-Button [9], "Digital Photography of Food Method" (DPFM) [10-13], and wearable microcameras [14]). However, such methods have been suggested to have some limitations, e.g., the need for a mobile device for recording food pictures [15]. A user-friendly tool is the Bite Counter (Bite Technologies, Pendleton, USA) [16]; it looks similar to a watch, but has an integrated accelerometer and gyroscope, and it records wrist movements while eating.

Undoubtedly, such tools are promising and provide encouraging results, but they still present several limitations. Some of the tools are not meant for daily use (they are uncomfortable and require training to be used). Not least, most of the tools have been validated only on a small set of food types, and their validity seems to vary according to food type [16]. Therefore, the aim of the present study was to assess the feasibility and reliability of automatic food intake measurement via a bite counting (AFIM-BC) device in estimating energy intake from energy-dense foods and how eventual estimation errors are dependent on the specific food composition.

\section{Materials and Methods}

\subsection{Participants}

Healthy volunteers were recruited at the University of Padova using recruiting flyers. Inclusion criteria were age over 18 years, no allergies to food served during the eating session, no cognitive impairment, and the ability to read and speak in Italian. Before study participation, the volunteers were asked to sign informed consent forms.

According to the Italian legislation framework, approval from the Institutional Review Board was not needed.

Before the eating session, participants underwent anthropometric assessment. The anthropometric assessment was performed by registered dieticians. Weight, height, hip and waist circumference were measured. Body mass index (BMI) and waist-to-hip ratio (WHR) were calculated.

\subsection{Study Device}

The device used in the present study was the Bite Counter (Bite Technologies, Pendleton, USA), a tool that looks similar to a watch (and that operates as a digital watch when it is not counting bites). It must be worn on the wrist of the dominant hand, since it records wrist movements while eating. The rationale of the Bite Counter is that the wrist movements that occur in the act of bringing food to the mouth (using hands or other utensils) present unique patterns that are recognized and recorded by the Bite Counter through the gyroscope.

The application software of the Bite Counter was employed to download and save the data (number of bites) of each eating session (by connecting each device to the computer in which the Bite Counter software was installed).

\subsection{Study Procedures}

Subjects were observed in a McDonald's restaurant in the Veneto region (Italy). The McDonald's restaurant was chosen because it allowed for the consumption of standardized meals in terms of meal size, calorie content, and nutrient content. Each subject chose the food items he or she preferred among those available. The nutritional facts of each food item chosen were available on the Italian McDonald's website (https://www.mcdonalds.it/) and are reported in Table 1.

All subjects finished their meal, and the nutritional facts of the meal of each subject are reported in Table 2. 
Table 1. Nutritional information for food items included in the study.

\begin{tabular}{|c|c|c|c|c|c|c|c|c|}
\hline & Energy & Protein & Carbs & Fat & Saturated Fat & Sodium & Sugar & Dietary Fiber \\
\hline CHICKEN McNUGGETS $^{\circledR}$ (6 pieces) & 268 & 17 & 18 & 14 & 1.7 & 1.2 & 0.4 & 1.5 \\
\hline CRISPY McBACON ${ }^{\circledR}$ & 492 & 27 & 32 & 28 & 11 & 1.7 & 6.3 & 1.8 \\
\hline $\mathrm{McCHICKEN}^{\circledR}$ & 428 & 21 & 46 & 17 & 2.3 & 1.9 & 6.5 & 2.8 \\
\hline CHICKEN COUNTRY & 479 & 35 & 46 & 17 & 3.5 & 2.7 & 5.3 & 2.2 \\
\hline HAMBURGER & 254 & 13 & 30 & 8.8 & 3.5 & 1.3 & 6.6 & 2 \\
\hline $1955^{\circledR}$ & 625 & 35 & 49 & 31 & 11 & 2.3 & 13 & 4 \\
\hline CHICKENBURGER & 344 & 12 & 37 & 16 & 2.9 & 1.5 & 4.4 & 2.5 \\
\hline QUARTER POUNDER ${ }^{\circledR}$ DELUXE & 533 & 30 & 35 & 30 & 12 & 1.9 & 8.4 & 2.7 \\
\hline CHICKEN WINGS & 227 & 22 & 3.6 & 14 & 3.3 & 2.5 & 1.1 & 0 \\
\hline FRENCH FRIES (Regular) & 239 & 2.7 & 29 & 12 & 1.1 & 0.55 & 0.3 & 2.9 \\
\hline FRENCH FRIES (Medium) & 341 & 3.98 & 42 & 17 & 1.5 & 0.79 & 0.5 & 4.2 \\
\hline VERTIGO FRENCH FRIES (Medium) & 330 & 3.8 & 41 & 16 & 1.7 & 1.9 & 0.7 & 6.1 \\
\hline SALAD & 118 & 9.2 & 4 & 6.7 & 4.3 & 0.49 & 2.9 & 2.4 \\
\hline GREEK SALAD & 210 & 11 & 6 & 15 & 8 & 2.2 & 4 & 4 \\
\hline APPLE SLICES & 41 & 0.2 & 8.7 & 0.2 & 0 & 0 & 6.6 & 2.1 \\
\hline
\end{tabular}


Table 2. Nutritional information for food items included in the study.

\begin{tabular}{|c|c|c|c|c|c|c|c|c|c|c|c|}
\hline ID & Food Item 1 & Food Item 2 & Food Item 3 & $\begin{array}{l}\text { Energy } \\
\text { (Kcal) }\end{array}$ & $\begin{array}{l}\text { Protein } \\
\text { (g) }\end{array}$ & $\begin{array}{l}\text { Carbs } \\
(\mathrm{g})\end{array}$ & Fat $(g)$ & $\begin{array}{l}\text { Saturated } \\
\text { Fat }(g)\end{array}$ & $\begin{array}{l}\text { Sodium } \\
\text { (g) }\end{array}$ & $\begin{array}{l}\text { Sugar } \\
\text { (g) }\end{array}$ & $\begin{array}{r}\text { Dietary } \\
\text { Fiber (g) }\end{array}$ \\
\hline 1 & CHICKEN McNUGGETS $^{\circledR}$ & FRENCH FRIES (Medium) & \multirow{10}{*}{$\begin{array}{l}\text { FRENCH FRIES } \\
\quad \text { (Regular) }\end{array}$} & 609 & 20.98 & 60 & 31 & 3.2 & 1.99 & 0.9 & 5.7 \\
\hline 2 & CRISPY McBACON ${ }^{\circledR}$ & FRENCH FRIES (Medium) & & 833 & 30.98 & 74 & 45 & 12.5 & 2.49 & 6.8 & 6 \\
\hline 3 & $\mathrm{McCHICKEN}^{\circledR}$ & FRENCH FRIES (Medium) & & 769 & 24.98 & 88 & 34 & 3.8 & 2.69 & 7 & 7 \\
\hline 5 & CHICKEN COUNTRY & FRENCH FRIES (Medium) & & 820 & 38.98 & 88 & 34 & 5 & 3.49 & 5.8 & 6.4 \\
\hline 6 & HAMBURGER & CHICKENBURGER & & 837 & 27.7 & 96 & 36.8 & 7.5 & 3.35 & 11.3 & 7.4 \\
\hline 7 & CHICKEN COUNTRY & FRENCH FRIES (Medium) & & 820 & 38.98 & 88 & 34 & 5 & 3.49 & 5.8 & 6.4 \\
\hline 8 & $1955^{\circledR}$ & $\begin{array}{l}\text { VERTIGO FRENCH FRIES } \\
\text { (Medium) }\end{array}$ & & 955 & 38.8 & 90 & 47 & 12.7 & 4.2 & 13.7 & 10.4 \\
\hline 9 & McCHICKEN ${ }^{\circledR}$ & FRENCH FRIES (Medium) & & 769 & 24.98 & 88 & 34 & 3.8 & 2.69 & 7 & 7 \\
\hline 10 & $1955^{\circledR}$ & $\begin{array}{l}\text { VERTIGO FRENCH FRIES } \\
\text { (Medium) }\end{array}$ & & 955 & 38.8 & 90 & 47 & 12.7 & 4.2 & 13.7 & 10.4 \\
\hline 11 & $1955^{\circledR}$ & $\begin{array}{c}\text { VERTIGO FRENCH FRIES } \\
\text { (Medium) }\end{array}$ & & 955 & 38.8 & 90 & 47 & 12.7 & 4.2 & 13.7 & 10.4 \\
\hline 12 & \multirow{2}{*}{\multicolumn{3}{|c|}{$\begin{array}{l}\text { MENU HAPPY MEAL }{ }^{\circledR}: \text { HAMBURGER + FRENCH FRIES (Regular) + APPLE SLICES } \\
\text { CHICKEN MCNUGGETS }{ }^{\circledR}\end{array}$}} & 534 & 15.9 & 67.7 & 21 & 4.6 & 1.85 & 13.5 & 7 \\
\hline 13 & & & & 268 & 17 & 18 & 14 & 1.7 & 1.2 & 0.4 & 1.5 \\
\hline 14 & McCHICKEN $^{\circledR}$ & \multicolumn{2}{|l|}{$\begin{array}{l}\text { VERTIGO FRENCH FRIES } \\
\text { (Medium) }\end{array}$} & 758 & 24.8 & 87 & 33 & 4 & 3.8 & 7.2 & 8.9 \\
\hline 15 & CHICKEN McNUGGETS $^{\circledR}$ & \multicolumn{2}{|l|}{ FRENCH FRIES (Medium) } & 609 & 20.98 & 60 & 31 & 3.2 & 1.99 & 0.9 & 5.7 \\
\hline 18 & $\begin{array}{l}\text { QUARTER POUNDER }{ }^{\circledR} \\
\text { DELUXE }\end{array}$ & \multicolumn{2}{|l|}{$\begin{array}{l}\text { VERTIGO FRENCH FRIES } \\
\text { (Medium) }\end{array}$} & 863 & 33.8 & 76 & 46 & 13.7 & 3.8 & 9.1 & 8.8 \\
\hline
\end{tabular}

McNUGGETS ${ }^{\circledR}=$ six pieces. 
The eating session of each subject-one at a time- was supervised by trained researchers. Each subject was asked to wear the Bite Counter on the wrist of the dominant hand, to turn the device on before the first bite and to turn it off once they finished the meal. Each subject was told to eat always with the dominant hand and to drink with the other hand (beverages were excluded from the analysis to limit the variability). All participants adhered to the instructions for using the Bite Counter. They all ate using their hands, except the three subjects who had a salad (who ate it using a fork).

\subsection{Power Analysis}

The study was designed to estimate the association between bites and the different nutrients composing the food administered to study participants. A linear regression model was assumed to describe this association and an effect size of 0.5 was assumed as the target minimal association to be detected. With an alpha level of 0.05 and a power of 0.80 , a two-tailed test based on the F distribution (non-centrality parameter of 3 ) indicates that 18 subjects are needed to be enrolled. Computations have been made using G-Power [17] software.

\subsection{Statistical Analysis}

Descriptive statistics were reported as medians (I and III quartiles) for continuous variables and percentages (absolute number) for categorical variables.

Energy intake, based on the number of bites recorded by the Bite Counter, was estimated using three different approaches described by Salley J. (2013) [18], Scisco et al. (2014) [19], and Salley et al. (2016) [20]. Salley J. (2013) [18] provided two different equations (one for males and one for females) to estimate the amount of kcal per bite. Such an equation is based on the subject's age, weight, and height. Scisco et al. [19] considered that a bite corresponds to $11 \mathrm{kcal}$ for females and to $17 \mathrm{kcal}$ for males (which is similar to the amount of kcal per bite resulting from the application of the equations presented by Salley J (2013)). Salley et al. (2016) [20] provided an equation based on age, sex, and anthropometric measures (height, weight, and WHR) to estimate the number of kcal per bite.

The agreement between the subject's actual caloric intake, based on the nutritional information reported in Table 2, and the estimated caloric intake by each approach was assessed using a Bland-Altman plot [21]. The association of the content of seven nutritional values with the error in estimated caloric intake, defined as the McDonald's nutritional information minus the estimated caloric intake based on Bite counter, was evaluated across the approaches mentioned above to understand how the accuracy of estimated energy intake may vary relative to different nutritional content values. In addition, we tested the correlation between the number of bites and nutritional content values. Statistical analysis was performed using the R software system (version 3.5.1) [22].

\section{Results}

Of the eighteen subjects enrolled, 11 were women. The median age was 28.5 years. Regarding anthropometric measures, subjects presented a median BMI of 21.72 and a median WHR of 0.80 . None of the subjects were obese. The median actual caloric intake and nutritional values, with I and III quartiles, are reported in Table 3. 
Table 3. Descriptive statistics of subjects enrolled in the study. Continuous variables are reported as medians [I and III quartiles], and categorical variables are reported as percentages (absolute number).

\begin{tabular}{|c|c|c|}
\hline Subject Characteristics & & Overall $(n=18)$ \\
\hline Age (years) & & $28.50[26.00,29.75]$ \\
\hline \multirow{2}{*}{ Gender } & Female & $61.1(11)$ \\
\hline & Male & $38.9(7)$ \\
\hline BMI & & $21.72[19.31,24.83]$ \\
\hline Waist & & $74.50[68.75,84.50]$ \\
\hline Hip & & $95.00[93.00,95.75]$ \\
\hline WHR & & $0.80[0.74,0.90]$ \\
\hline Real caloric intake (Kcal) & & $769.00[591.00,836.00]$ \\
\hline Protein content $(\mathrm{g})$ & & $29.34[21.93,38.80]$ \\
\hline Carbohydrate content (g) & & $81.50[61.92,88.00]$ \\
\hline Fat content $(\mathrm{g})$ & & $34.00[29.50,42.95]$ \\
\hline Saturated fat content $(\mathrm{g})$ & & $6.05[3.85,12.20]$ \\
\hline Sodium content $(\mathrm{g})$ & & $3.42[2.54,3.80]$ \\
\hline Sugars content $(\mathrm{g})$ & & $7.10[5.80,12.95]$ \\
\hline Dietary fiber content (g) & & $7.00[5.78,8.53]$ \\
\hline Number of bites & & $36.50[34.00,45.25]$ \\
\hline
\end{tabular}

The accuracy of caloric intakes were significantly different among the methods used, with the Salley (2016) approach showing the lowest median error (Salley (2013) 229.27 95\% C.I. 109.97, 367.19; Scisco (2014) 242.00 95\% C.I. 53.75, 355.75; and Salley 201656.81 95\% C.I. $-179.16,183.43 ; p$-value $=0.01$ ). Associations between the error in estimated energy intake and content in $(\mathrm{g})$ of nutritional values for each approach are reported in Table 4. The rows where the author's names of the proposed approaches are presented contain the percentiles of errors in the estimated caloric intake in Kcal, computed as the difference between the McDonald's nutritional information and the estimated caloric intake.

Regarding the Salley (2013) approach, carbohydrate and fat content levels were significantly different across categories of errors in estimated caloric intake defined by quartiles ( $p$-value 0.030 and 0.017, respectively), whereas only fat content was significantly different for the Scisco (2014) approach ( $p$-value 0.027). Regarding the Salley (2016) method, only carbohydrate and dietary fiber content levels were significantly different across errors of estimated energy intake ( $p$-value 0.040 and 0.032 , respectively). Figure 1 shows the Bland-Altman plots used to evaluate the agreement between the actual caloric intake and the estimated caloric intake by each approach. Overall, Salley (2013) and Scisco (2014) methods showed similar agreement patterns and they overestimate the caloric intake of nearly $200 \mathrm{Kcal}$, on average. Salley (2016) method showed larger variability in the differences (95\% C.I. $-470.12,456.50)$ than Salley (2013) (95\% C.I. -161.82, 584.21) and Scisco (2014) (95\% C.I. -178.85, 579.18). Figure 2 reports the relationship between the nutritional content values and error in estimated caloric intake by the different approaches. 
Table 4. Nutritional content values across percentiles of errors in estimated caloric intake in Kcal for Salley (2013), Scisco (2014), and Salley (2016). The rows where the author's names are shown report the errors in the estimated caloric intake in Kcal. The results are reported as the median [I and III quartiles]. Differences between median values were assessed using the Kruskal-Wallis test.

\begin{tabular}{|c|c|c|c|c|c|c|}
\hline Nutritional Value & 0-20 Percentile & 20-40 Percentile & 40-60 Percentile & 60-80 Percentile & 80-100 Percentile & $p$-Value \\
\hline Salley (2013) & {$[-198.2,80.48]$} & {$[80.48,174.74]$} & {$[174.74,289.95]$} & {$[289.95,383.95]$} & {$[383.95,484.47]$} & \\
\hline Protein content (g) & $26.60[19.40,36.05]$ & $20.98[18.44,29.98]$ & $29.39[23.98,35.09]$ & $24.98[24.89,31.89]$ & $34.89[30.16,38.80]$ & 0.84 \\
\hline Carbohydrate content (g) & $29.50[15.90,48.00]$ & $67.70[63.85,77.85]$ & $82.00[72.00,88.00]$ & $88.00[87.50,89.00]$ & $90.00[86.00,91.50]$ & 0.03 \\
\hline Fat content $(\mathrm{g})$ & $23.70[20.52,25.77]$ & $31.00[26.00,32.50]$ & $34.00[33.25,37.00]$ & $34.00[33.50,40.50]$ & $46.00[42.95,47.00]$ & 0.017 \\
\hline Saturated fat content $(\mathrm{g})$ & $8.45[5.75,10.18]$ & $4.60[3.90,4.80]$ & $4.40[3.65,7.17]$ & $4.00[3.90,8.35]$ & $12.60[11.25,12.70]$ & 0.314 \\
\hline Sodium content $(\mathrm{g})$ & $3.39[2.69,3.87]$ & $1.99[1.92,2.74]$ & $3.09[2.52,3.57]$ & $3.80[3.25,4.00]$ & $3.78[3.14,4.20]$ & 0.521 \\
\hline Sugar content $(\mathrm{g})$ & $8.05[3.92,11.72]$ & $5.80[3.35,9.65]$ & $6.40[4.57,7.53]$ & $7.20[7.10,10.45]$ & $12.50[10.18,13.70]$ & 0.447 \\
\hline Dietary fiber content $(\mathrm{g})$ & $4.25[3.38,5.30]$ & $6.40[6.05,6.70]$ & $6.70[6.23,7.45]$ & $8.90[7.95,9.65]$ & $8.90[7.05,10.40]$ & 0.106 \\
\hline Scisco $(2014)$ & {$[-179,26.6]$} & {$[26.6,167.2]$} & {$[167.2,293.8]$} & {$[293.8,361.2]$} & {$[361.2,448]$} & \\
\hline Protein content $(\mathrm{g})$ & $26.60[19.40,34.49]$ & $20.98[18.44,33.09]$ & $29.39[23.98,35.09]$ & $38.80[31.80,38.80]$ & $29.34[27.02,32.94]$ & 0.905 \\
\hline Carbohydrate content (g) & $43.50[15.90,73.75]$ & $60.00[50.50,63.85]$ & $82.00[72.00,88.00]$ & $90.00[88.50,90.00]$ & $89.00[84.50,91.50]$ & 0.052 \\
\hline Fat content $(\mathrm{g})$ & $26.85[22.02,30.25]$ & $22.70[21.85,26.85]$ & $34.00[33.25,37.00]$ & $47.00[40.00,47.00]$ & $40.90[36.10,45.50]$ & 0.027 \\
\hline Saturated fat content $(\mathrm{g})$ & $6.05[4.17,8.15]$ & $4.60[3.90,7.20]$ & $4.40[3.65,7.17]$ & $12.70[8.35,12.70]$ & $10.00[6.58,12.55]$ & 0.63 \\
\hline Sodium content $(\mathrm{g})$ & $3.54[2.92,3.87]$ & $1.99[1.92,2.59]$ & $3.09[2.52,3.57]$ & $4.20[4.00,4.20]$ & $3.02[2.64,3.56]$ & 0.176 \\
\hline Sugar content $(\mathrm{g})$ & $5.45[3.92,7.82]$ & $11.00[5.95,12.25]$ & $6.40[4.57,7.53]$ & $13.70[10.45,13.70]$ & $9.15[6.95,11.90]$ & 0.368 \\
\hline Dietary fiber content $(\mathrm{g})$ & $5.20[3.38,6.73]$ & $5.70[5.10,6.35]$ & $6.70[6.23,7.45]$ & $10.40[9.65,10.40]$ & $7.20[6.75,8.15]$ & 0.068 \\
\hline Salley (2016) & {$[-458.67,-224.52]$} & {$[-224.52,-40.98]$} & {$[-40.98,103.72]$} & {$[103.72,203.73]$} & {$[203.73,318.56]$} & \\
\hline Protein content $(\mathrm{g})$ & $26.60[19.40,34.49]$ & $20.98[20.98,33.09]$ & $29.39[22.71,35.09]$ & $38.80[31.80,38.80]$ & $29.34[27.02,32.94]$ & 0.95 \\
\hline Carbohydrate content (g) & $43.50[15.90,73.75]$ & $60.00[50.50,60.00]$ & $82.00[73.92,88.00]$ & $90.00[88.50,90.00]$ & $89.00[84.50,91.50]$ & 0.04 \\
\hline Fat content $(\mathrm{g})$ & $26.85[22.02,30.25]$ & $31.00[26.85,31.00]$ & $34.00[30.75,37.00]$ & $47.00[40.00,47.00]$ & $40.90[36.10,45.50]$ & 0.057 \\
\hline Saturated fat content $(\mathrm{g})$ & $6.05[4.17,8.15]$ & $3.20[3.20,6.50]$ & $4.80[4.40,7.17]$ & $12.70[8.35,12.70]$ & $10.00[6.58,12.55]$ & 0.495 \\
\hline Sodium content $(\mathrm{g})$ & $3.54[2.92,3.87]$ & $1.99[1.99,2.59]$ & $3.09[2.48,3.57]$ & $4.20[4.00,4.20]$ & $3.02[2.64,3.56]$ & 0.203 \\
\hline Sugar content $(\mathrm{g})$ & $5.45[3.92,7.82]$ & $0.90[0.90,5.95]$ & $8.05[6.70,10.20]$ & $13.70[10.45,13.70]$ & $9.15[6.95,11.90]$ & 0.299 \\
\hline Dietary fiber content $(\mathrm{g})$ & $5.20[3.38,6.73]$ & $5.70[5.10,5.70]$ & $7.00[6.85,7.45]$ & $10.40[9.65,10.40]$ & $7.20[6.75,8.15]$ & 0.032 \\
\hline
\end{tabular}



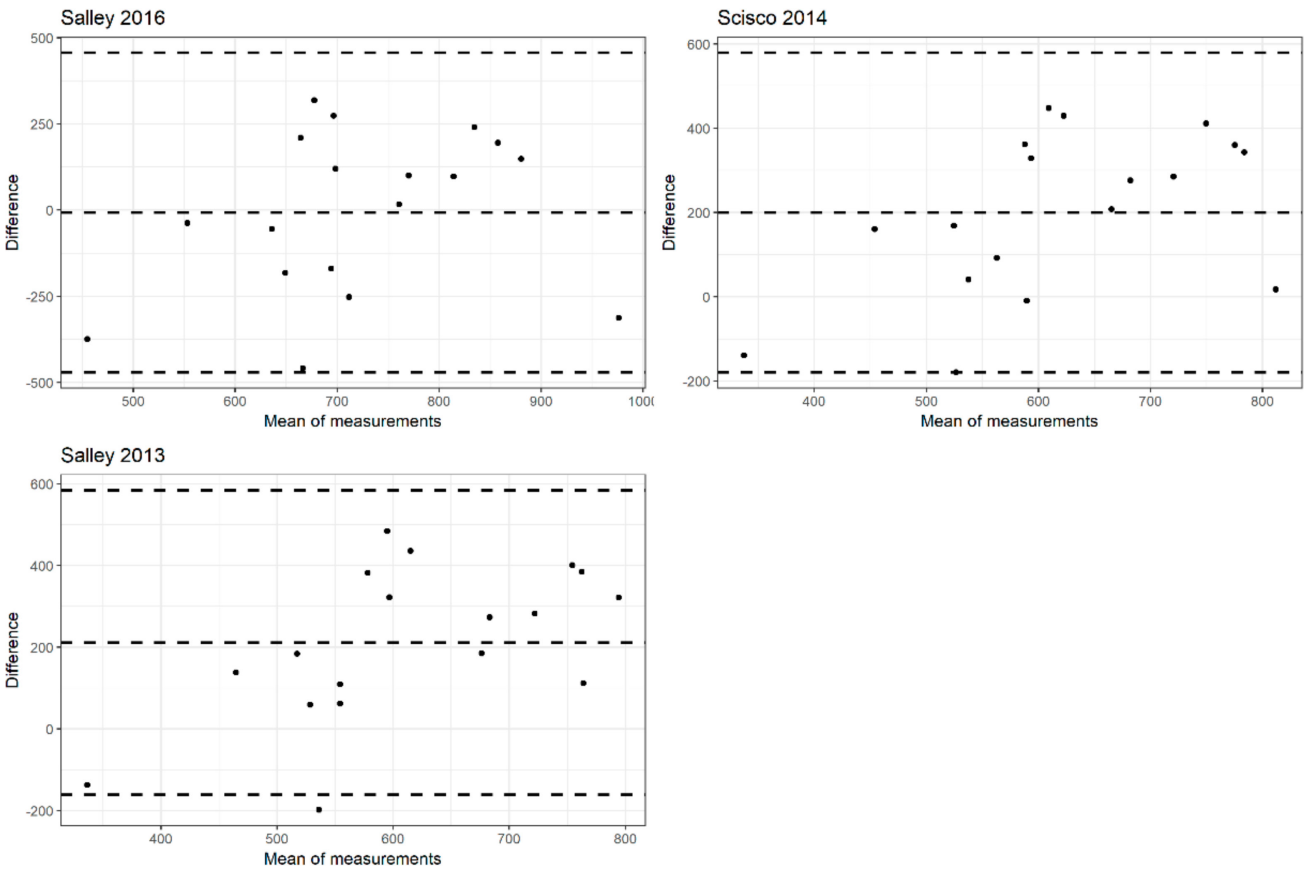

Figure 1. Bland-Altman plots to evaluate the agreement between the actual caloric intake and the estimated caloric intake in Kcal. The means of the measurements are reported on the $x$-axis, whereas the differences between the measurements (McDonald's nutritional information minus estimated caloric intake) are reported on the $y$-axis.
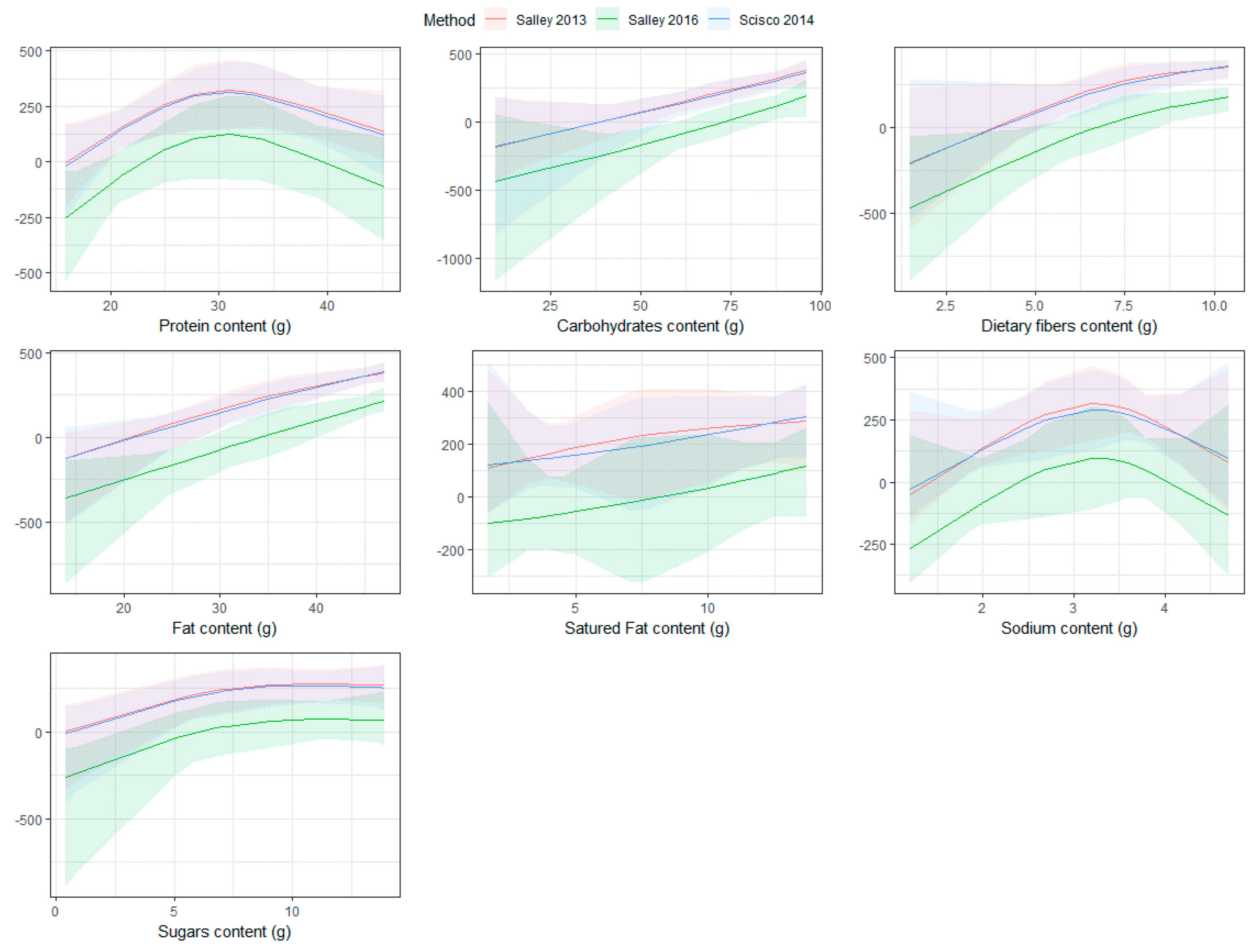

Figure 2. Association between nutritional values in (g), reported on the $x$-axis, and errors in estimated caloric intake in Kcal, reported on the $y$-axis. Lines and bands represent the estimated error and relative $95 \% \mathrm{CI}$, respectively. Colors represent the approach used to estimate caloric intake.

Salley (2016) systematically underestimates the caloric intake for lower levels of nutritional value, while Salley (2013) and Scisco (2014) systematically overestimate caloric intake. The overestimation 
increases at higher nutritional content levels, except for protein and sodium. Table 5 reports the association between the number of bites and the macronutrient content, measured as an increase in $(\mathrm{g})$ for one more bite with relative 95\% Confidence Interval (C.I.) and $p$-value.

Table 5. Association between the number of bites and nutritional values. Numbers are reported as the increase in $(\mathrm{g})$ for one more bite (95\% C.I.).

\begin{tabular}{ccc}
\hline Nutritional Value & Increase in $(\mathrm{g})$ for One More Bite & $p$-Value \\
\hline Protein content $(\mathrm{g})$ & $0.0981(-0.312,0.508)$ & 0.619 \\
Carbohydrate content & $-0.74(-1.84,0.364)$ & 0.175 \\
Fat content $(\mathrm{g})$ & $-0.253(-0.683,0.177)$ & 0.23 \\
Saturated fat content $(\mathrm{g})$ & $-0.0433(-0.235,0.148)$ & 0.639 \\
Sodium content $(\mathrm{g})$ & $0.0124(-0.0322,0.0569)$ & 0.565 \\
Sugar content $(\mathrm{g})$ & $-0.0889(-0.298,0.12)$ & 0.381 \\
Dietary fiber content $(\mathrm{g})$ & $-0.0606(-0.164,0.0427)$ & 0.231 \\
\hline
\end{tabular}

No significant association was found, as suggested by $95 \%$ C.I. that always include the 0 and $\mathrm{P}$-values always greater than 0.05. This pattern is also shown graphically in Figure 3.
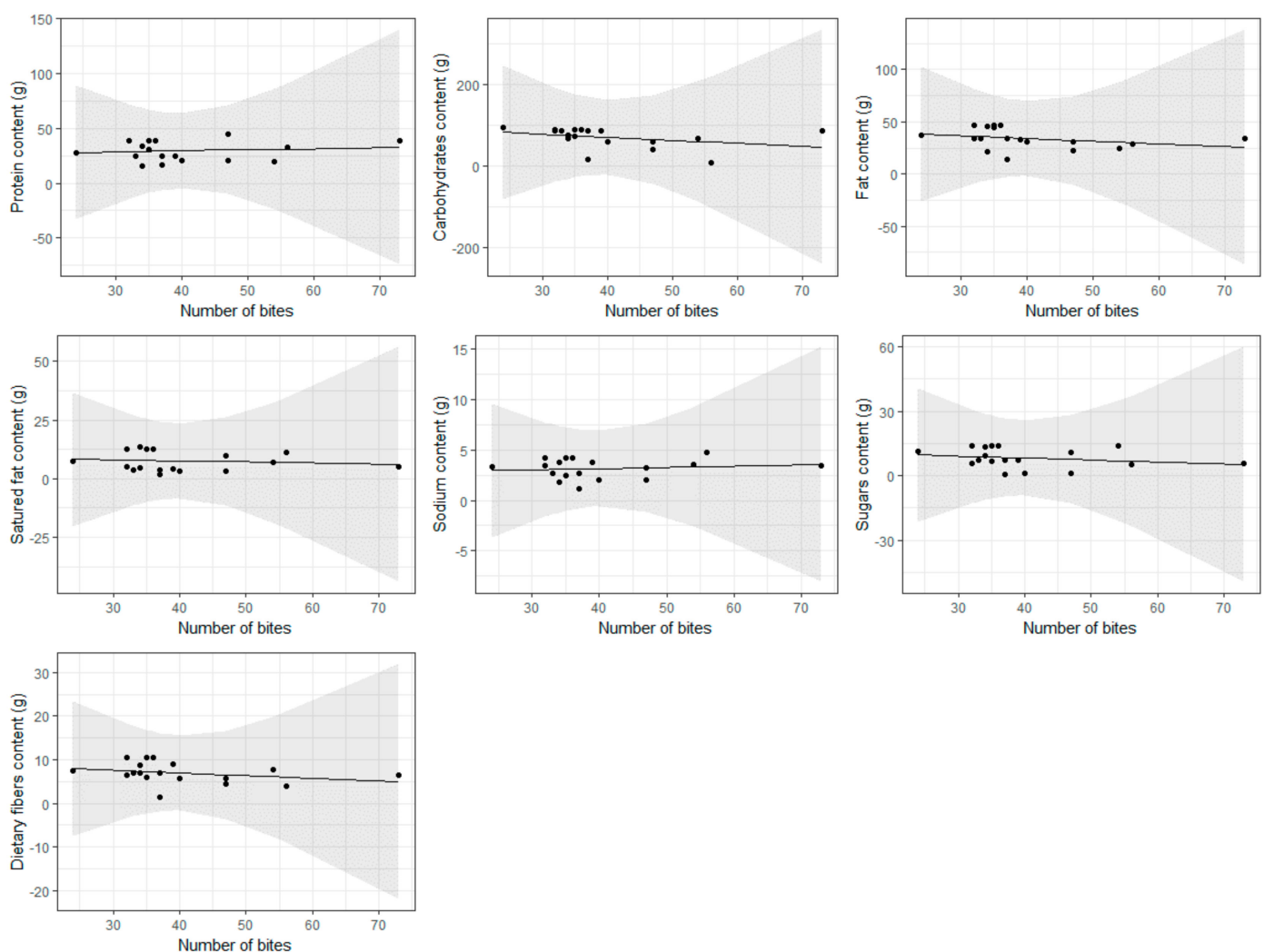

Figure 3. Association between the number of bites, reported on the $x$-axis, and nutritional values in (g), reported on the $y$-axis. Lines and bands represent the estimated error and relative $95 \%$ C.I., respectively.

\section{Discussion}

The present results showed that the accuracy of the Bite Counter in estimating energy intake varied according to the type and amount (especially for fat and carbohydrates) of macronutrients present and that this variability was independent of the number of bites recorded. Such findings are consistent with previous studies in the field. Wearable dietary assessment devices have been found to be accurate in the counting of bites in both controlled and uncontrolled settings [16,23] and to outperform energy estimation compared to that of self-reporting [20]. However, consistent with the 
results of the present study, Scisco et al. [19] showed that, even if significant, the correlation with actual energy intake is only moderate. In addition, it has been suggested that the validity of the Bite Counter (in counting the actual number of bites) is different according to food category and that the device is more accurate when subjects eat using their hands [16].

The present findings suggest that such wearable devices, although promising, still present several limitations. The main limiting factor is the variability in the accuracy of energy intake estimation according to the macronutrient content, especially if the device is employed to estimate energy intake from energy-dense foods. Such a limitation could depend on the type of utensils used, which have been shown to influence the wrist movements (e.g., the number of bites required to eat soup with a spoon is often underestimated because the movement of the wrist is reduced to not spill the soup [16]) and on the variability in the size of bite. However, it is worth pointing out that such a study was conducted in a controlled setting to minimize the interindividual variability in meal consumption. Subjects ate the meal under the supervision of the researcher, all ate using their hands (except for the three subjects who ate the salad) and were properly trained on the use of the device. Furthermore, the number of bites was found to be not associated with the macronutrient content. Therefore, such variability in estimating energy intake could be more likely related to the lack of a reliable and feasible algorithm to identify the energy intake from each bite.

AFIM-BC devices might be considered a promising opportunity for monitoring energy intake in the primary and secondary prevention of diet-related noncommunicable diseases. Therefore, the fact that the accuracy of the device in estimating energy intake is lower for high Kcal macronutrients, especially for fats and carbohydrates, is critical because it implies a poor performance of such devices in estimating energy intake from energy-dense foods. Measuring energy intake from such food items is of great interest. It has been widely demonstrated that the increasing availability of inexpensive, energy-dense food has led to an increase in obesity rates. Subjects who eat such types of food items are at risk of excessive daily caloric intake that together with sedentary behaviors, may result in weight gain $[24,25]$. As an example, subjects enrolled in the present study had a mean energy intake of $718 \mathrm{kcal}$, adding the energy $(168 \mathrm{kcal})$ of a medium-sized carbonated beverage (which was excluded from the analysis), resulted in an energy intake of $886 \mathrm{kcal}$ from a single meal, which represents almost half of the daily energy requirements (considering a daily requirement of $2000 \mathrm{kcal}$ ). Anyway, despite the potential limitations identified in the performance of the device, Turner-McGrievy et al. have shown that the use of the Bite Counter significantly correlates with weight loss [26,27], confirming the potentials of AFIM-BC devices employment in weight management programs.

\section{Conclusions}

Further research is needed to overcome the current limitations of wearable devices in estimating caloric intake, which is not independent of the food being eaten, and to improve the accuracy of the algorithms for the estimation of energy intake through the detection of wrist movement and, more generally, of mouthing activity. As an example, the Italian Ministry of Health (Directorate General for Food Hygiene and Safety and Nutrition) has recently funded the Notion (Measuring caloric intake at population level) research project aimed at developing a unique algorithm capable of estimating energy intake based on mouthing activity recorded by inertial sensors, independent of the type of device used [28]. Undoubtedly, deriving energy intake from mouthing activity is challenging, but itrepresents a promising opportunity from the public health perspective.

Author Contributions: Conceptualization, D.G.; Data curation, D.A.; Formal analysis, D.B.; Methodology, D.G.; Writing-original draft, G.L.

Funding: This research received no external funding.

Conflicts of Interest: The authors declare no conflict of interest 


\section{References}

1. Ezzati, M.; Riboli, E. Behavioral and dietary risk factors for noncommunicable diseases. N. Engl. J. Med. 2013, 369, 954-964. [CrossRef] [PubMed]

2. Who, J.; Consultation, F.E. Diet, Nutrition and the Prevention of Chronic Diseases; World Health Organ Tech. Rep Ser; World Health Organization: Geneva, Switzerland, 2003; Volume 916.

3. Hébert, J.R.; Hurley, T.G.; Steck, S.E.; Miller, D.R.; Tabung, F.K.; Peterson, K.E.; Kushi, L.H.; Frongillo, E.A. Considering the value of dietary assessment data in informing nutrition-related health policy. Adv. Nutr. Int. Rev. J. 2014, 5, 447-455. [CrossRef] [PubMed]

4. Thompson, F.E.; Subar, A.F.; Loria, C.M.; Reedy, J.L.; Baranowski, T. Need for technological innovation in dietary assessment. J. Am. Diet. Assoc. 2010, 110, 48-51. [CrossRef]

5. Vu, T.; Lin, F.; Alshurafa, N.; Xu, W. Wearable Food Intake Monitoring Technologies: A Comprehensive Review. Computers 2017, 6, 4. [CrossRef]

6. Fontana, J.M.; Higgins, J.A.; Schuckers, S.C.; Bellisle, F.; Pan, Z.; Melanson, E.L.; Neuman, M.R.; Sazonov, E. Energy intake estimation from counts of chews and swallows. Appetite 2015, 85, 14-21. [CrossRef]

7. Bi, Y.; Lv, M.; Song, C.; Xu, W.; Guan, N.; Yi, W. Autodietary: A wearable acoustic sensor system for food intake recognition in daily life. IEEE Sens. J. 2016, 16, 806-816. [CrossRef]

8. Kalantarian, H.; Alshurafa, N.; Le, T.; Sarrafzadeh, M. Monitoring eating habits using a piezoelectric sensor-based necklace. Comput. Biol. Med. 2015, 58, 46-55. [CrossRef]

9. Jia, W.; Chen, H.-C.; Yue, Y.; Li, Z.; Fernstrom, J.; Bai, Y.; Li, C.; Sun, M. Accuracy of food portion size estimation from digital pictures acquired by a chest-worn camera. Public Health Nutr. 2014, 17, 1671-1681. [CrossRef]

10. Martin, C.K.; Nicklas, T.; Gunturk, B.; Correa, J.B.; Allen, H.R.; Champagne, C. Measuring food intake with digital photography. J. Hum. Nutr. Diet. 2014, 27, 72-81. [CrossRef] [PubMed]

11. Martin, C.K.; Newton, R.L.; Anton, S.D.; Allen, H.R.; Alfonso, A.; Han, H.; Stewart, T.; Sothern, M.; Williamson, D.A. Measurement of children's food intake with digital photography and the effects of second servings upon food intake. Eat. Behav. 2007, 8, 148-156. [CrossRef]

12. Martin, C.K.; Han, H.; Coulon, S.M.; Allen, H.R.; Champagne, C.M.; Anton, S.D. A novel method to remotely measure food intake of free-living people in real-time: The remote food photography method (rfpm). Br. J. Nutr. 2009, 101, 446-456. [CrossRef] [PubMed]

13. Martin, C.K.; Correa, J.B.; Han, H.; Allen, H.R.; Rood, J.C.; Champagne, C.M.; Gunturk, B.K.; Bray, G.A. Validity of the Remote Food Photography Method (RFPM) for Estimating Energy and Nutrient Intake in Near Real-Time. Obesity 2012, 20, 891-899. [CrossRef]

14. Pettitt, C.; Liu, J.; Kwasnicki, R.M.; Yang, G.-Z.; Preston, T.; Frost, G. A pilot study to determine whether using a lightweight, wearable micro-camera improves dietary assessment accuracy and offers information on macronutrients and eating rate. Br. J. Nutr. 2016, 115, 160-167. [CrossRef]

15. Bonilla, C.; Brauer, P.; Royall, D.; Keller, H.; Hanning, R.M.; DiCenso, A. Use of electronic dietary assessment tools in primary care: An interdisciplinary perspective. BMC Med. Inform. Decis. Mak. 2015, 15, 14. [CrossRef] [PubMed]

16. Desendorf, J.; Bassett, D.R.; Raynor, H.A.; Coe, D.P. Validity of the Bite Counter device in a controlled laboratory setting. Eat. Behav. 2014, 15, 502-504. [CrossRef] [PubMed]

17. Faul, F.; Erdfelder, E.; Buchner, A.; Lang, A.-G. Statistical power analyses using G* Power 3.1: Tests for correlation and regression analyses. Behav. Res. Methods 2009, 41, 1149-1160. [CrossRef] [PubMed]

18. Salley, J. Accuracy of a Bite-Count Based Calorie Estimate Compared to Human Estimates with and without Calorie Information Available. Master's Thesis, Clemson University, Clemson, SC, USA, 2013.

19. Scisco, J.L.; Muth, E.R.; Hoover, A.W. Examining the Utility of a Bite-Count-Based Measure of Eating Activity in Free-Living Human Beings. J. Acad. Nutr. Diet. 2014, 114, 464-469. [CrossRef]

20. Salley, J.N.; Hoover, A.W.; Wilson, M.L.; Muth, E.R. Comparison between human and bite-based methods of estimating caloric intake. J. Acad. Nutr. Diet. 2016, 116, 1568-1577. [CrossRef] [PubMed]

21. Bland, J.M.; Altman, D. Statistical methods for assessing agreement between two methods of clinical measurement. Lancet 1986, 327, 307-310. [CrossRef]

22. R Core Team. R: A Language and Environment for Statistical Computing; R Foundation for Statistical Computing: Vienna, Austria, 2017. 
23. Dong, Y.; Hoover, A.; Scisco, J.; Muth, E. A new method for measuring meal intake in humans via automated wrist motion tracking. Appl. Psychophysiol. Biofeedback 2012, 37, 205-215. [CrossRef]

24. Pérez-Escamilla, R.; Obbagy, J.E.; Altman, J.M.; Essery, E.V.; McGrane, M.M.; Wong, Y.P.; Spahn, J.M.; Williams, C.L. Dietary energy density and body weight in adults and children: A systematic review. J. Acad. Nutr. Diet. 2012, 112, 671-684. [CrossRef]

25. Stelmach-Mardas, M.; Rodacki, T.; Dobrowolska-Iwanek, J.; Brzozowska, A.; Walkowiak, J.; Wojtanowska-Krosniak, A.; Zagrodzki, P.; Bechthold, A.; Mardas, M.; Boeing, H. Link between food energy density and body weight changes in obese adults. Nutrients 2016, 8, 229. [CrossRef] [PubMed]

26. Turner-McGrievy, G.M.; Boutté, A.; Crimarco, A.; Wilcox, S.; Hutto, B.E.; Hoover, A.; Muth, E.R. Byte by bite: Use of a mobile Bite Counter and weekly behavioral challenges to promote weight loss. Smart Health 2017, 3, 20-26. [CrossRef] [PubMed]

27. Turner-McGrievy, G.M.; Wilcox, S.; Boutté, A.; Hutto, B.E.; Singletary, C.; Muth, E.R.; Hoover, A.W. The Dietary Intervention to Enhance Tracking with Mobile Devices (DIET Mobile) Study: A 6-Month Randomized Weight Loss Trial. Obesity 2017, 25, 1336-1342. [CrossRef]

28. Fuscà, E.; Bolzon, A.; Buratin, A.; Ruffolo, M.; Berchialla, P.; Gregori, D.; Perissinotto, E.; Baldi, I. NOTION Group. Measuring Caloric Intake at the Population Level (NOTION): Protocol for an Experimental Study. JMIR Res. Protoc. 2019, 8, e12116.

(C) 2019 by the authors. Licensee MDPI, Basel, Switzerland. This article is an open access article distributed under the terms and conditions of the Creative Commons Attribution (CC BY) license (http://creativecommons.org/licenses/by/4.0/). 